\title{
Phase Transformation Kinetics and the Assessment of Equilibrium and Metastable States
}

\author{
Jicheng Zhao and M.R. Notis \\ Department of Materials Science and Engineering \\ Lehigh University, Bethlehem, PA $18015-3195$
}

(Submitted May 22, 1992; in revised form February 12, 1993)

\begin{abstract}
The general characteristics of phase transformation kinetics during cooling and heating are introduced. It is demonstrated that the cooling process always depresses the phase boundaries away from equilibrium and towards lower temperatures; similarly, the heating process always shifts the phase boundaries to higher temperatures. Moreover, the larger the cooling or heating rate, the larger the discrepancy. According to this observation, the reliability of cooling and heating data (irrespective of the methods used to determine them: electrical resistance, dilatometry, etc.) for phase diagram assessments is discussed. The principle for correct assessment of metastable phase information is also briefly introduced. It is pointed out that each kind of metastable phase has its own transformationstart temperature, $T_{s}\left(M_{s}\right.$, etc.), during cooling. More specifically, each kind of martensite has its own $M_{s .}$ Examples are shown for $\mathrm{Fe}-\mathrm{Ni}$, Fe-Mn, and Ti-Cr alloys.
\end{abstract}

\section{Introduction}

There are generally two broad categories of methods for the determination of phase diagrams. The first category of methods detects the phase boundaries (transuses) by means of thermal, physical, chemical, or mechanical property changes during

This paper was presented at the Thermodynamics and Phase Equilibria of Metastable Phases Symposium at the Spring TMS Meeting, March 1-4, 1992, in San Diego. The symposium was organized by Philip Nash, Illinois Institute of Technology, and Ricardo Schwarz, Los Alamos National Laboratory. cooling and/or heating of an alloy, as shown in Fig. 1, and therefore studies the approach of a system to the equilibrium state. When an alloy with composition $X_{0}$ is slowly cooled to $T_{s}, \alpha$ phase starts to form in the alloy. Because the thermal, physical, chemical, and mechanical properties of the $\alpha$ phase are different from those of the $\gamma$ phase, by monitoring the variation of a specific property (electrical resistance, for example) with temperature, or by measurement of the temperature as a function of time (thermal analysis), the transformation-start temperature $\left(T_{s}\right)$ and transformation-finish temperature $\left(T_{f}\right)$ can be evaluated by locating the temperatures at which the property vs temperature or temperature vs time curves display a change of slope, as shown in Fig. 1(b).

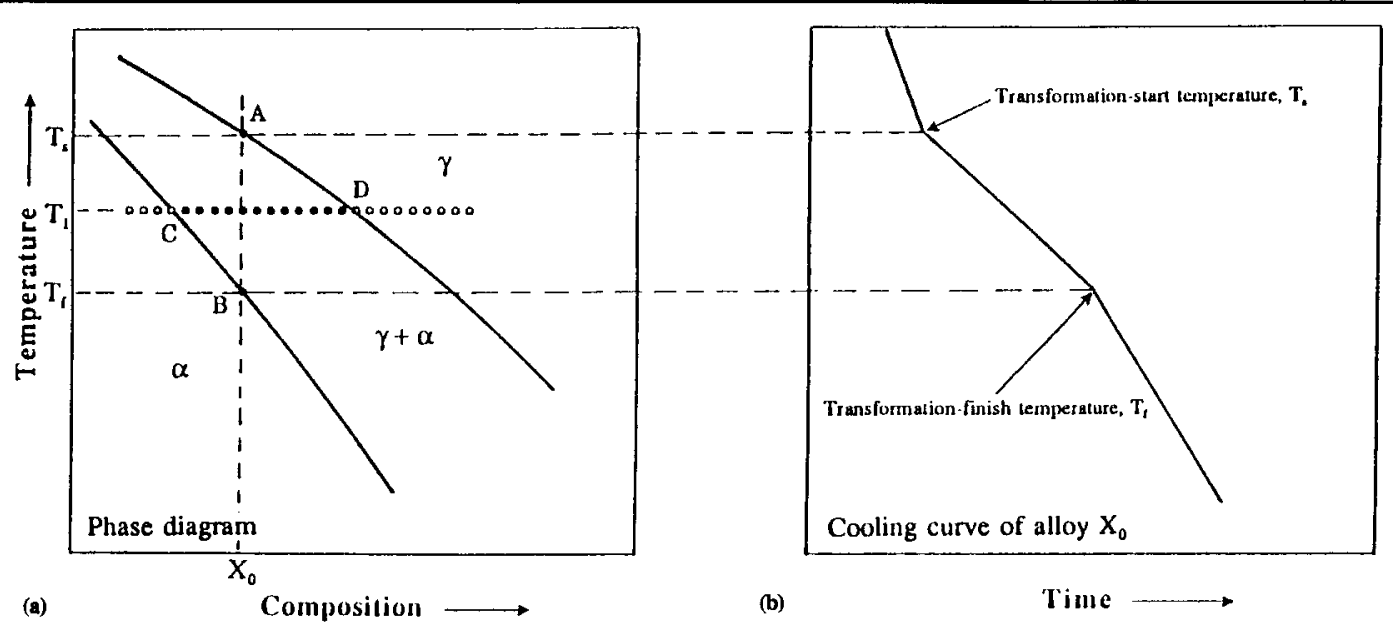

Fig. 1 Schematic diagram showing methods for the determination of phase diagrams. (a) Schematic phase diagram. (b) Schematic cooling curve of a specific alloy $X_{0}$. 


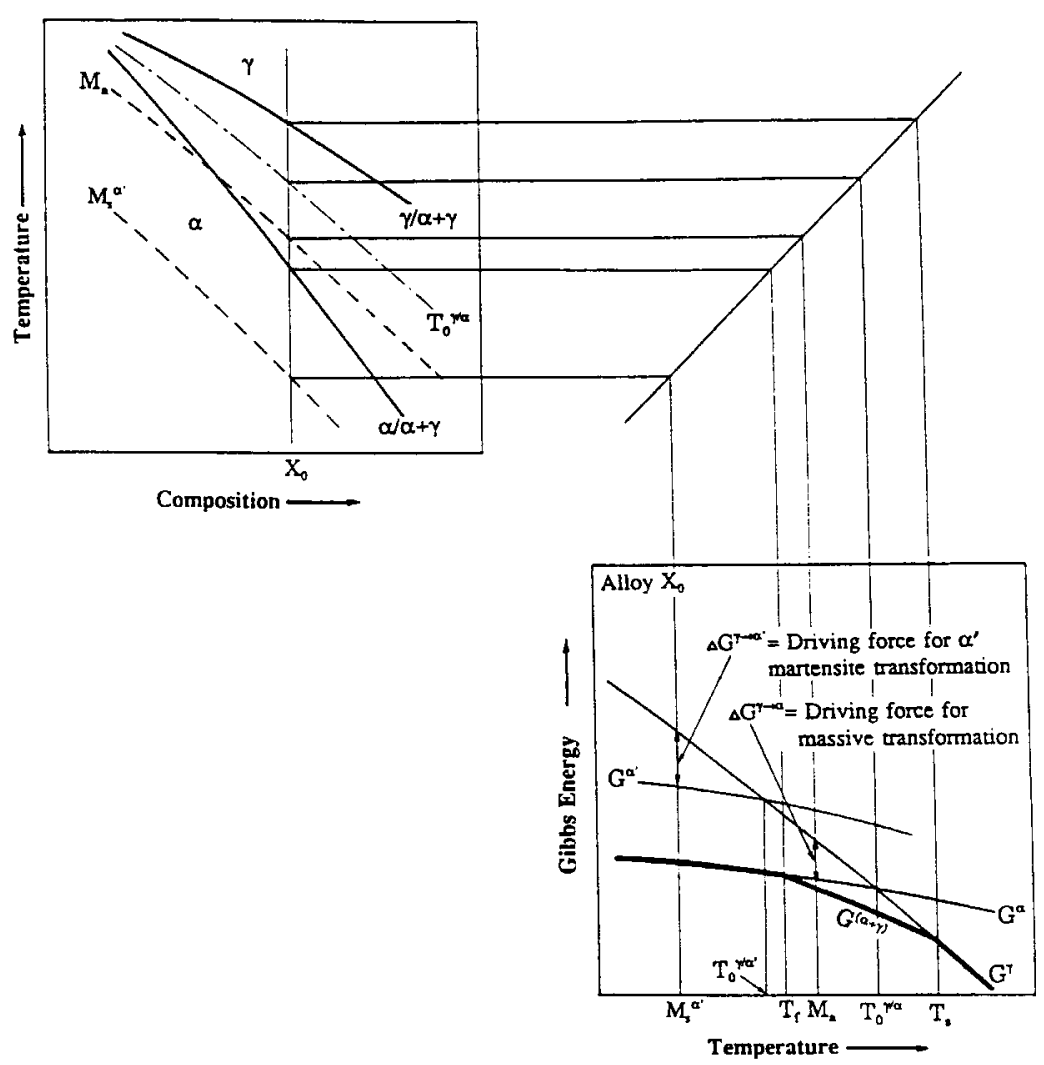

Fig. 2 Schematic diagram illustrating the variation of Gibbs energy of various stable and metastable phases with temperature. Heavy line represents the equilibrium (stable) phase(s) at each temperature. See the text for detail.

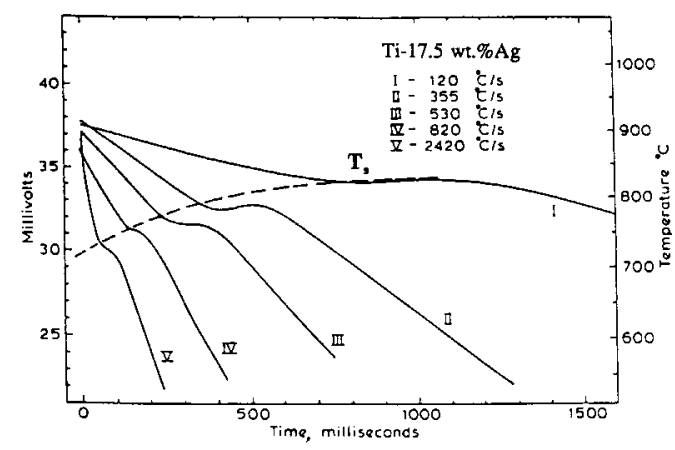

Fig. 3 Series of cooling curves of the Ti-17.5 wt.\% Ag alloy showing the variation of the $\beta \rightarrow \alpha$ transformation-start temperatures, $T_{s}$, with the cooling rate. By connecting the $T_{s}$ points of several cooling curves, a CCT diagram is obtained. From Plichta et al. 4

The other category of methods employs equilibrated alloys or diffusion couple specimens and therefore studies the behavior of the system in the equilibrium or local equilibrium state. A series of alloys with different compositions can be annealed at a specific temperature, say $T_{1}$, as shown in Fig. 1. Some property is measured as a function of composition to test for differences in the state of equilibrium. For example, $\mathrm{X}$-ray diffraction (XRD) may be used for lattice parameter measurement, and the

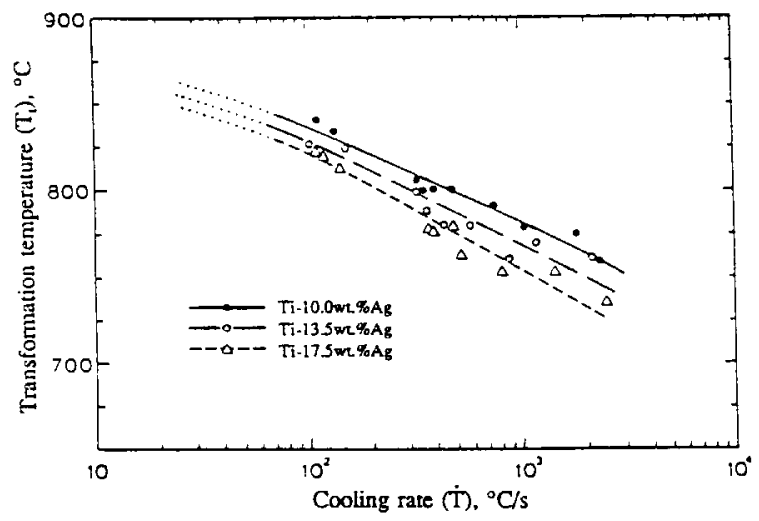

Fig. 4 Transformation temperature vs cooling rate $\left(T_{t}-\dot{T}\right)$ diagram of three Ti-Ag alloys. From Plichta et al. ${ }^{4}$

phase boundaries (point $C$ and $D$ in Fig. 1) can be located by sharp changes in the lattice parameter (or some other property) vs composition. An alternative method, which takes advantage of the local equilibrium at phase interfaces, detects phase boundaries by means of diffusion couple specimens or equilibrated alloys using techniques such as electron probe microanalysis (EPMA); this category of methods is dealt with separately. 


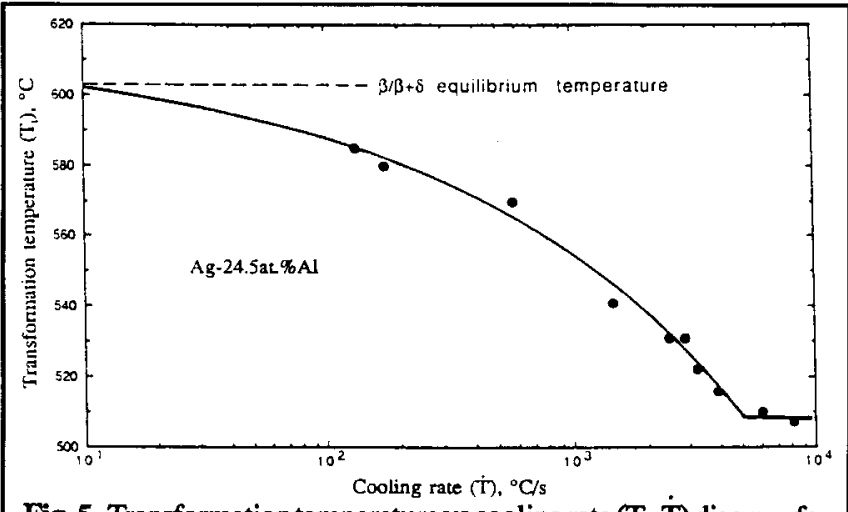

Fig.5 Transformation temperature vs cooling rate $\left(T_{t}-T\right)$ diagram for the $\mathrm{Ag}-24.5$ at.\% Al alloy. Data from Hawbolt and Massalski. ${ }^{6}$

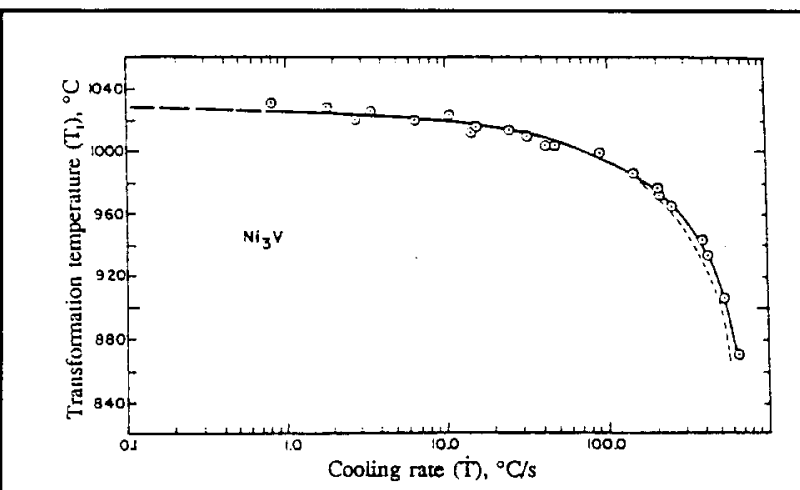

Fig. 6 Transformation temperature vs cooling rate $\left(T_{t}-\dot{T}\right)$ diagram of the order-disorder transformation in $\mathrm{Ni}_{3} \mathrm{~V}$. From Perepezko. ${ }^{7}$

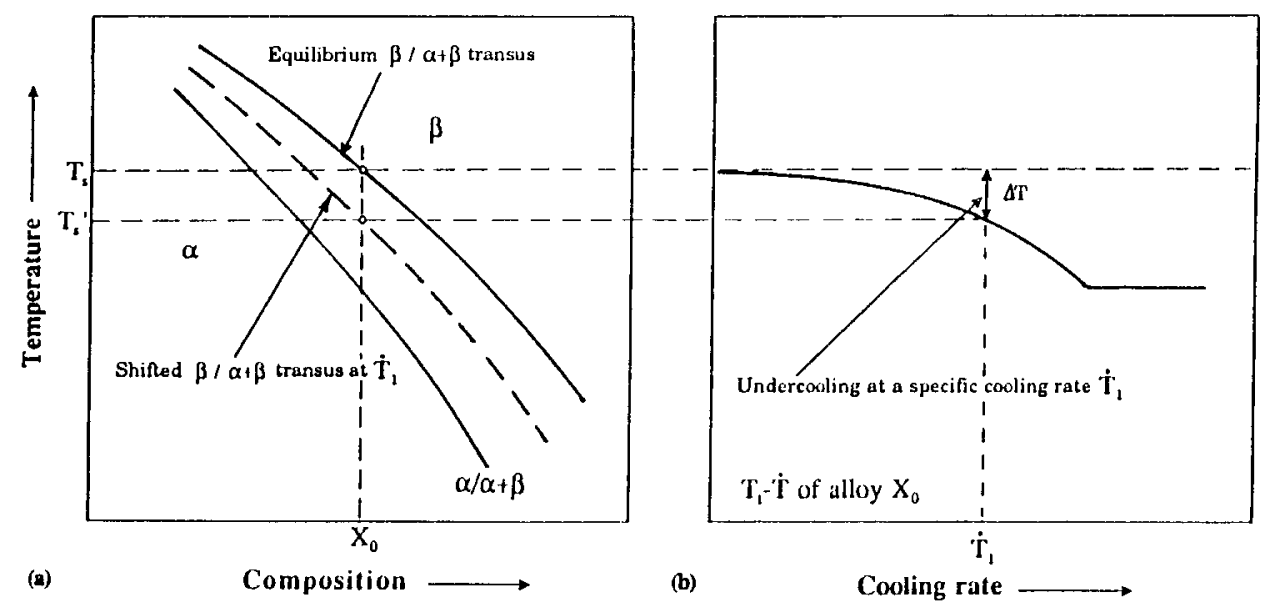

Fig. 7 Schematic diagram showing the shifting of the phase boundary (transus) with cooling rate used for the determination. (a) Schematic phase diagram. (b) Schematic $T_{t}-\mathrm{T}$ diagram of a specific alloy $X_{0}$.

For the first category of methods, except for the influence of specimen preparation ${ }^{1}$ on the measured transformation temperatures, there are certain general rules that govern all the cooling and heating processes and thus influence the measured phase boundaries. This review is meant to introduce the general principles concerning cooling and heating transformation kinetics as related to phase diagram determination; emphasis is placed on how the cooling and heating processes shift the phase boundaries away from the equilibrium state, often towards metastable states.

Equilibrium states and metastable states are differentiated by their Gibbs energy. An equilibrium state (phase) is the lowest Gibbs energy state (phase) a system can attain under specific external constraints (i.e. temperature, pressure, etc.). A metastable state (phase) has a higher Gibbs energy than the equilibrium state, but is still stable against fluctuation (i.e. $d G=0$ ). ${ }^{2}$

To understand the formation of equilibrium and metastable phases during cooling, it is worthwhile to examine the temperature dependence of their Gibbs energy, as shown in Fig. 2. The equilibrium phase of alloy $X_{0}$ at each temperature is indicated by the heavy line (with the lowest Gibbs energy). At temperatures higher than $\mathrm{T}_{\mathrm{s}}$, the Gibbs energy of the $\gamma$ phase, $G^{\gamma}$, is lower than the Gibbs energy of the $\alpha$ phase, $G^{\alpha}$, so the $\gamma$ phase is the stable phase. At a temperature between $\mathrm{T}_{\mathrm{s}}$ and $\mathrm{T}_{0}^{\gamma / \alpha}(\mathrm{de}-$ fined as the temperature at which $\left.G^{\gamma}=G^{\alpha}\right)$, although $G^{\gamma}$ is still lower than $G^{\alpha}$, the Gibbs energy of the $(\alpha+\gamma)$ two-phase mixture, $G^{(\alpha+\gamma)}$, is the lowest, so the $(\alpha+\gamma)$ two-phase mixture is the equilibrium state. However, the $\gamma \rightarrow(\alpha+\gamma)$ transformation can only be realized by long-range diffusion and thus could take a significantly long time to take place. When the temperature is lower than $\mathrm{T}_{0}^{\gamma / \alpha}, G^{\alpha}$ is lower than $G^{\gamma}$, and therefore direct $\gamma \rightarrow \alpha$ massive transformation (which produces a massive $\alpha$ phase with composition exactly the same as the $\gamma$ phase, and involves only local diffusion at the transformation front) becomes thermodynamically possible. However, this transformation can only be realized at a temperature, $\mathrm{M}_{\mathrm{a}}$, at which the driving force, $\Delta G^{\gamma \rightarrow \alpha}$, is large enough to initiate a massive $\alpha$ nucleus. At temperatures below $\mathrm{T}_{\mathrm{f}}, G^{\alpha}$ is the lowest, thus the $\alpha$ phase becomes the stable phase. Suppose a metastable phase, $\alpha^{\prime}$ martensite, exists in this system; then its Gibbs energy, $G^{\alpha^{\prime}}$, should be above $G^{\alpha}$, and correspondingly, $\mathrm{T}_{0}^{\gamma / \alpha^{\prime}}$ (as defined by $G^{\gamma}=G^{\alpha^{\prime}}$ ) should be lower than $\mathrm{T}_{0}^{\gamma / \alpha}$, as shown in Fig. 2. But the $\alpha^{\prime}$ martensite transformation can only take place at a temperature, $\mathrm{M}_{\mathrm{s}}^{\alpha^{\prime}}$ (which is below $\mathrm{T}_{0}^{\gamma / \alpha^{\prime}}$ ), at which the driving force for the $\alpha^{\prime}$ martensite transformation, $\Delta G^{\gamma \rightarrow \alpha^{\prime}}$, is 
large enough to initiate a martensite nucleus. If other metastable phases exist and their Gibbs energies are higher than $G^{\alpha^{\prime}}$, they can be formed only at temperatures below $\mathrm{M}_{\mathrm{s}}^{\alpha^{\prime}}$. In this connection, the number of possible metastable phases increases with lower temperatures.

However, with respect to kinetics we should know the conditions under which these metastable phases are formed during cooling, or more specifically, at what temperatures and what cooling rates these phases are formed and how the temperatures vary with the cooling rate. It will be shown that a simple and general rule holds for all these metastable phases.

It is extremely advantageous for assessment programs, such as the Alloy Phase Diagram Program, ${ }^{3}$ to include metastable phase information in the assessment of alloy systems because metastable phase information is often as valuable as equilib-

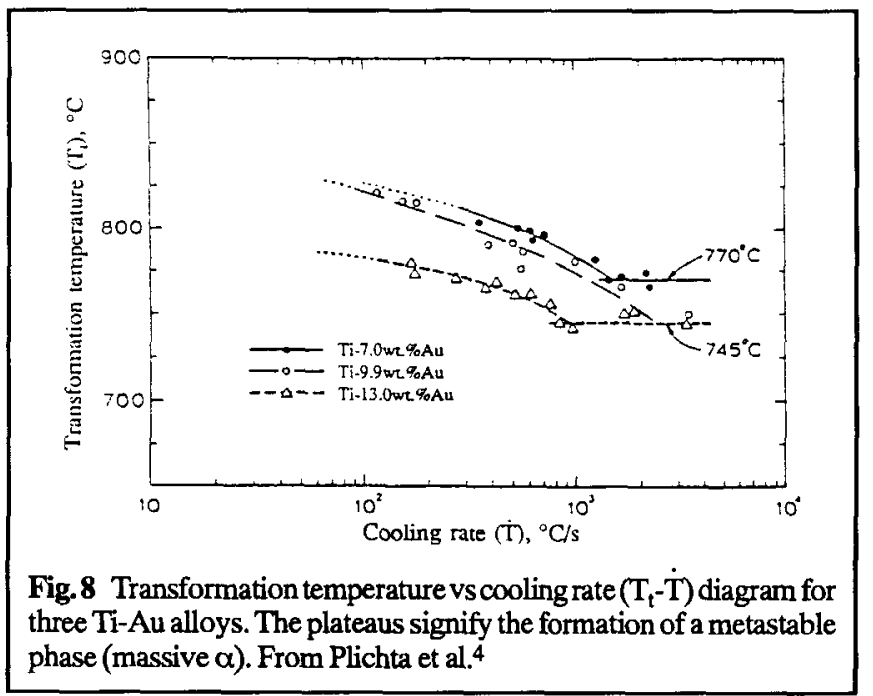

rium phase diagrams in many practical applications. However, a correct and reliable assessment of metastable phases also requires considerable understanding of the formation kinetics of those metastable phases. Examples are used to illustrate this point.

\section{Shifting of Phase Boundaries with the Cooling Rate}

Theoretically, only when an infinitesimally small cooling rate (thus an infinitely long cooling time) is used, can we detect the truly equilibrium phase boundaries. In this connection, equilibrium is never attended by a normal cooling process. It is well established that a certain undercooling is necessary to nucleate a particle of a new phase with a size above some critical value. In other words, the equilibrium phase boundaries are normally shifted towards lower temperatures (to produce a certain undercooling) during the cooling process. With increasing cooling rate, the formation of a critical nucleus becomes more difficult, and so does the diffusion process; thus greater undercooling is necessary. An example is shown in Fig. 3 for a $\mathrm{Ti}-17.5 \mathrm{wt} . \% \mathrm{Ag}\left(8.6\right.$ at. \%) alloy; ${ }^{4}$ it is clear that the higher the cooling rate, the lower is $\mathrm{T}_{\mathrm{s}}$. By connecting the $\mathrm{T}_{\mathrm{s}}$ points of a series of cooling curves, as shown by the dashed line in Fig. 3, we obtain the so-called "continuous cooling transformation" (CCT) diagram.

An alternative way to describe the cooling behavior is to directly plot the transformation temperature $\left(T_{t}\right)$ versus the cooling rate $(\dot{\mathrm{T}})$, as shown in Fig. 4, again for Ti-Ag alloys. ${ }^{4}$ The $C C T$ and $T_{t}-\dot{T}$ diagrams are equivalent because both record the relationship between the transformation temperature and the cooling rate. For the remainder of this paper, the $T_{t}-T$ diagram is employed to describe the cooling and heating transformation kinetics.

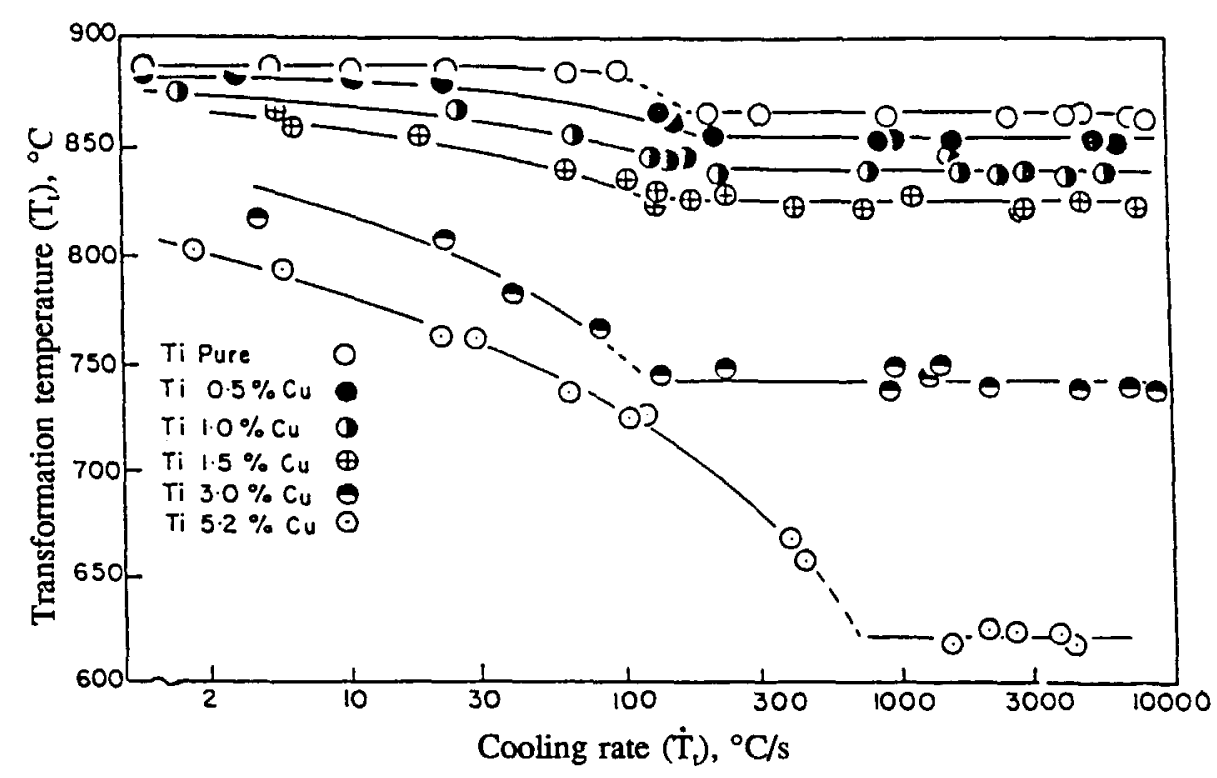

Fig. 9 Transformation temperature vs cooling rate $\left(\mathrm{T}_{t}-\mathrm{T}\right)$ diagram of $\mathrm{Ti}$ and $\mathrm{Ti}-\mathrm{Cu}$ alloys. The plateaus signify the formation of metastable phases. From Srivastava and Parr. ${ }^{9}$ Composition in atomic percent. 


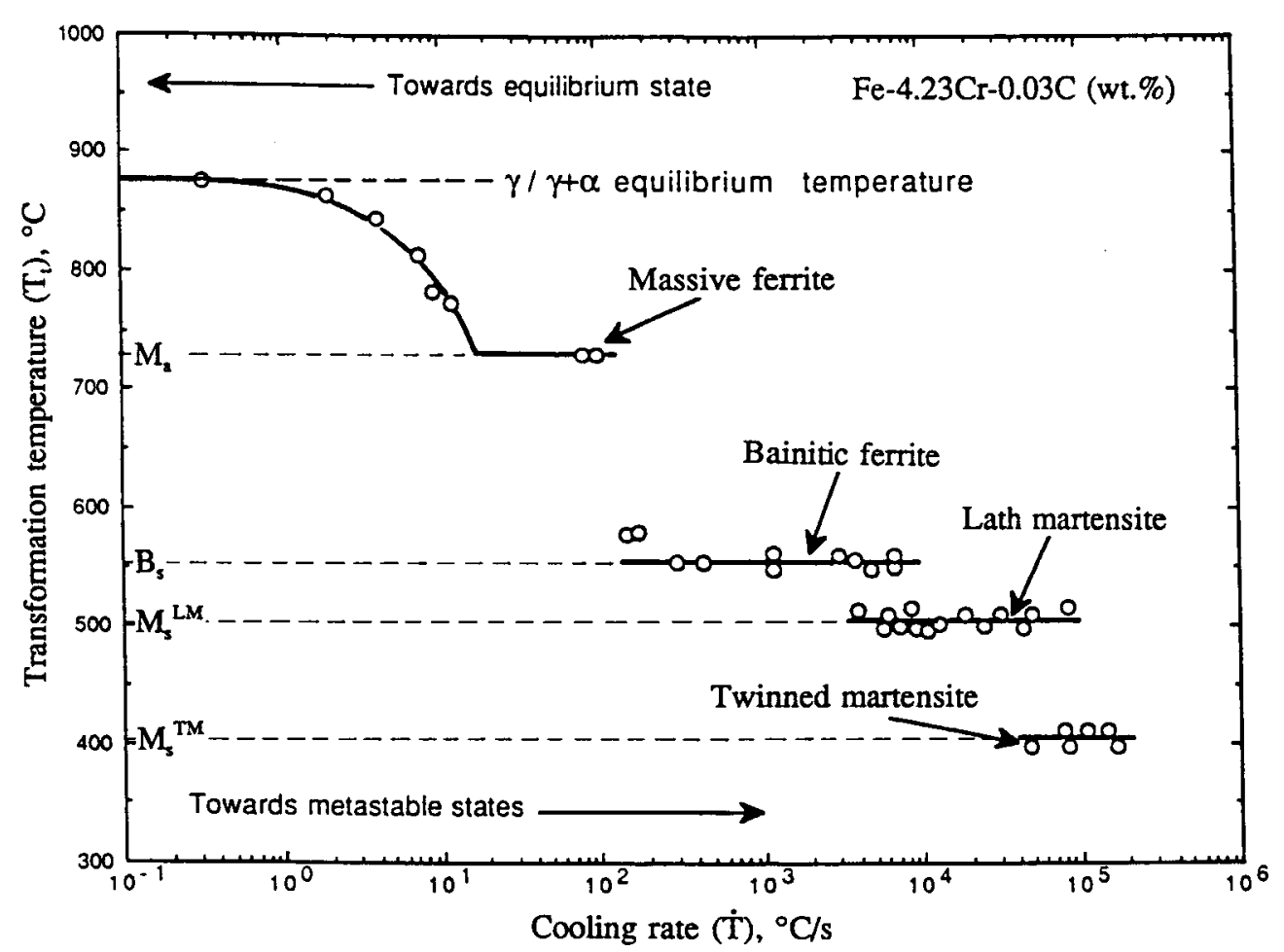

Fig. 10 Transformation temperature vs cooling rate $\left(\mathrm{T}_{t}-\dot{\mathrm{T}}\right)$ diagram of $\mathrm{Fe}-4.23 \mathrm{Cr}-0.03 \mathrm{C}(\mathrm{wt} . \%)$ alloy (steel) showing the formation of four metastable phases: massive ferrite, bainitic ferrite, lath martensite, and twinned martensite. Each metastable phase possesses its own transformation-start temperature $\left(\mathrm{M}_{\mathrm{a}}, \mathrm{B}_{\mathrm{s}}\right.$, and $\left.\mathrm{M}_{\mathrm{s}}\right)$, which is independent of cooling rate. Data from Mirzayev et al. ${ }^{10}$

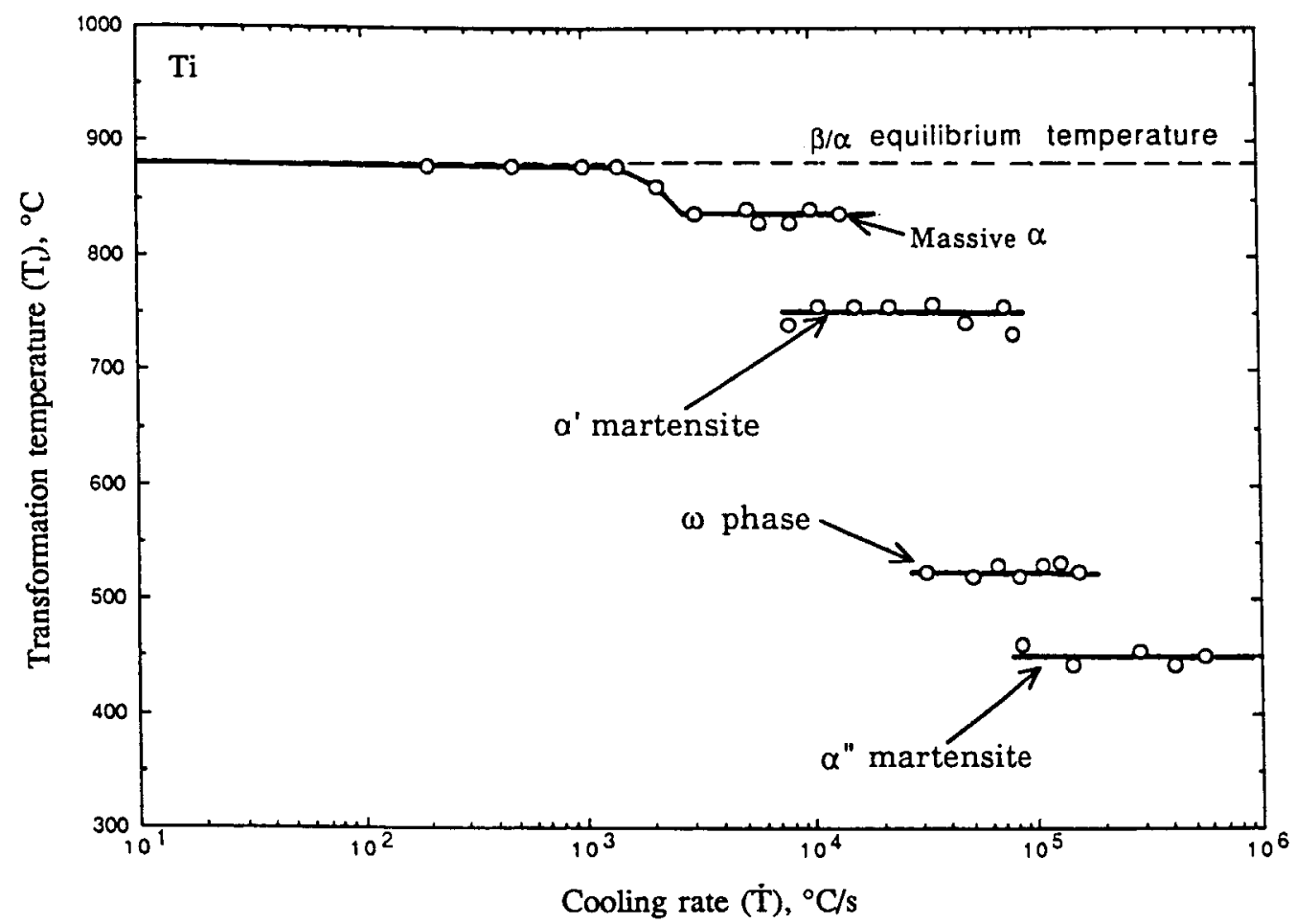

Fig. 11 Transformation temperature vs cooling rate $\left(T_{t}-\dot{T}\right)$ diagram of pure Ti showing the formation of four metastable phases: massive $\alpha, \alpha^{\prime}$ martensite, $\omega$ phase, and $\alpha^{\prime \prime}$ martensite. Each metastable phase has its own transformation-start temperature. Data from Mirzayev and Schastlivtsev. ${ }^{11}$ 
The lowering of the $T_{s}$ with $\dot{T}$ is a general phenomenon that holds for every alloy. Systematic investigations always confirm this kinetic behavior. For steels, many of the results are collected in compendia of CCT diagrams. 5 Two other examples are shown here for $\mathrm{Ag}-24.5$ at.\% Al (Fig. 5) ${ }^{6}$ and $\mathrm{Ni}_{3} \mathrm{~V}$ (Fig. 6). ${ }^{7}$

Comparison of a schematic phase diagram and a corresponding $T_{t}-T$ diagram can be used to demonstrate and emphasize the shifting of the phase boundaries as a function of cooling rate, as shown in Fig. 7. At a cooling rate $\dot{T}_{1}$, the equilibrium

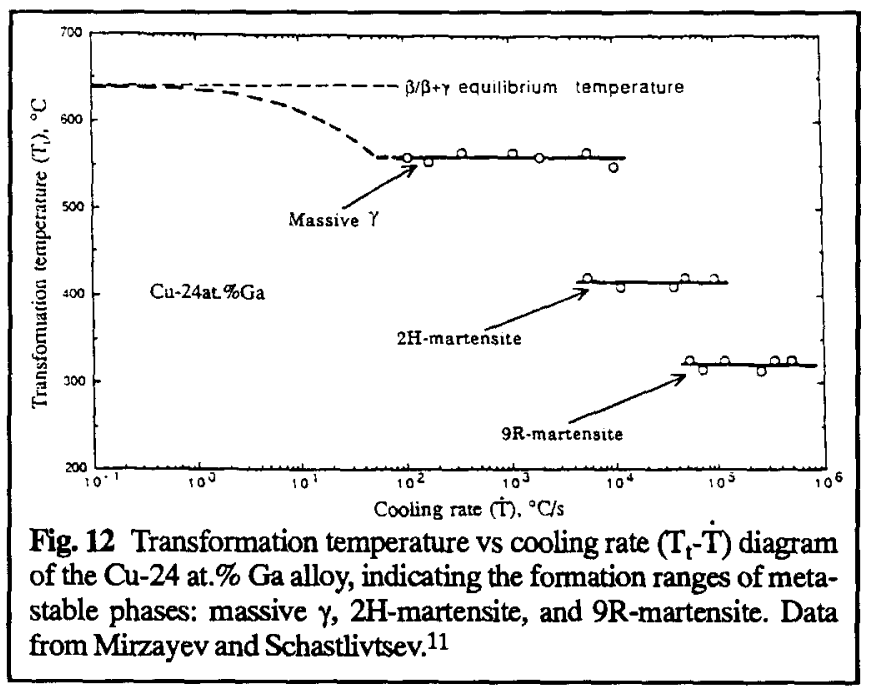

cooling transformation-start temperature $T_{s}$ (on the equilibrium $\beta /(\alpha+\beta)$ transus) of alloy $X_{0}$ is depressed to a temperature $T_{s}{ }^{\prime}$ with an undercooling of $\Delta T=T_{s}-T_{s}{ }^{\prime}$. $T_{s}$ will be further depressed at higher cooling rates.

\section{Formation of Metastable Phases During Cooling}

Above a certain critical cooling rate (CCR), $1000^{\circ} \mathrm{C} / \mathrm{s}$ for Ti$13 \mathrm{wt} . \% \mathrm{Au}$ (3.5 at.\%) as shown in Fig. $8,{ }^{4}$ the transformationstart temperature becomes independent of the cooling rate, i.e. a plateau forms in the $T_{t}-T$ diagram. This plateau corresponds to the formation of a metastable "massive transformation" product; as mentioned previously, this type of transformation is generally believed to involve only local diffusion at the transformation interface. The corresponding massive transformation-start temperature is conventionally designated as $\mathrm{M}_{\mathrm{a}}$. The fact that $\mathrm{M}_{\mathrm{a}}$ is independent of the cooling rate implies that long-range diffusion no longer plays a dominant role in this type of transformation because long-range diffusion is timedependent and thus should be cooling rate (T) dependent as well. It is believed that interface movement is the controlling factor of massive transformations. ${ }^{8}$ Similar experimental results are found over a wide range of compositions in the $\mathrm{Ti}-\mathrm{Cu}$ system (Fig. 9), ${ }^{9}$ and demonstrate the diversity of systems for which this behavior is seen.

At still higher cooling rates, other metastable phases can be formed. To facilitate our understanding, an example may be chosen from a ferrous alloy: the transformation observed upon

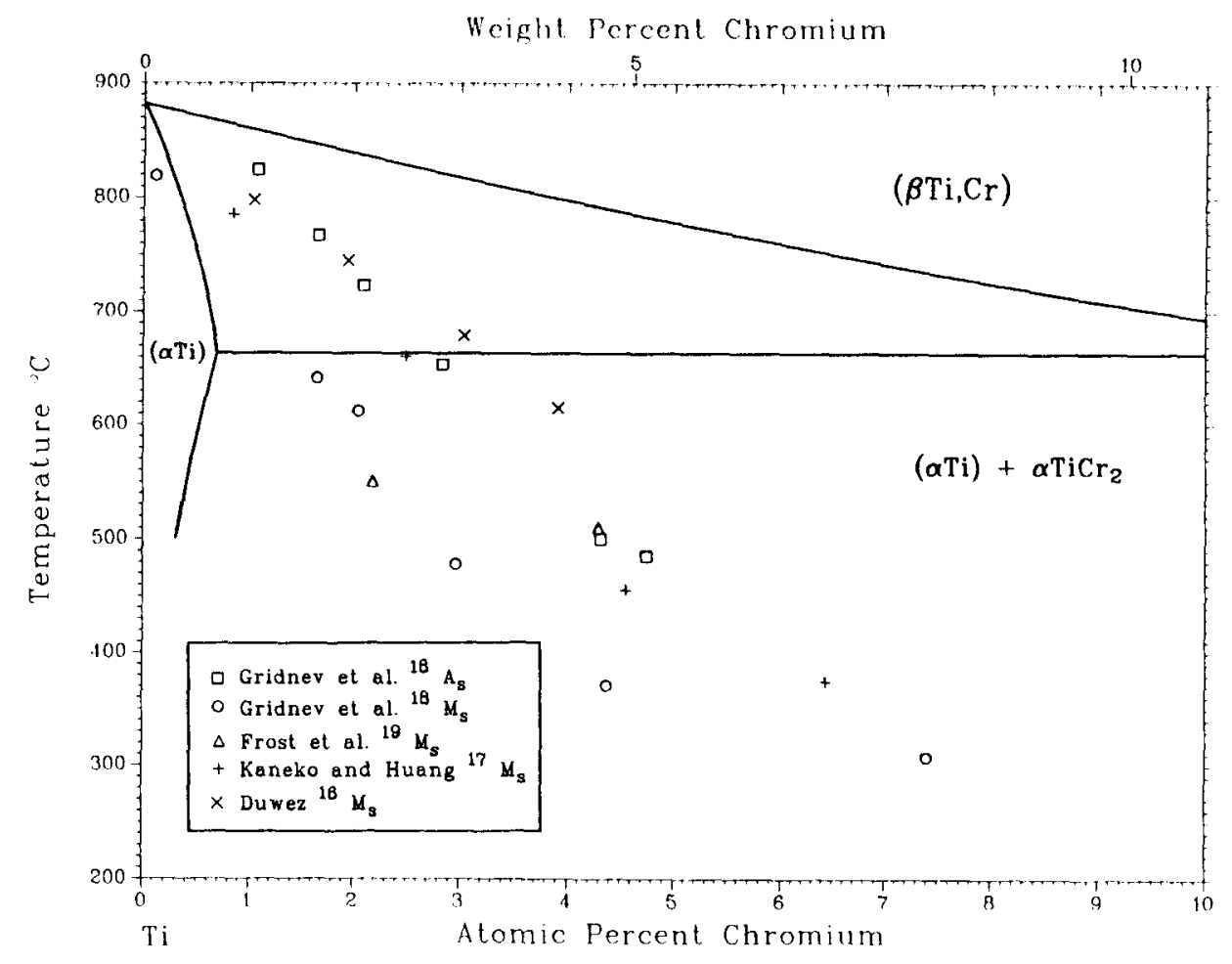

Fig. 13 The " $M_{s}$ " points of Ti-Cr alloys compiled by Murray 15 . Experimental data from Ref. 16 to 19. 
cooling an $\mathrm{Fe}-4.3 \mathrm{wt} . \% \mathrm{Cr}-0.03 \mathrm{wt} . \% \mathrm{C}$ alloy (4.6 at.\% Cr-0.14 at.\% C). The $\mathrm{T}_{\mathrm{t}}$-T diagram for this alloy is shown in Fig.10.10 Again it is clear that the higher the $T$, the lower the $T_{s}$ until the massive transformation plateau is reached, in this case for $\mathrm{T}>10^{\circ} \mathrm{C} / \mathrm{s}$, as described above. When the cooling rate reaches above $100^{\circ} \mathrm{C} / \mathrm{s}$, bainitic ferrite is formed, with a bainitic transformation-start temperature, $\mathrm{B}_{\mathrm{s}}$, independent of the cooling rate. As higher and higher cooling rates are reached, lath martensite and twinned martensite are formed. The $M_{s}$ for each of these martensite forms is also independent of the cooling rate. Moreover, although each metastable phase is formed at a certain cooling-rate range, this range may overlap that of another metastable phase; within this overlapping range, both kinds of metastable phases can be formed, as shown in Fig. 10.

It is clear that each metastable phase has its own $T_{\mathbf{s}}$, which is independent of $\dot{T}$. Correspondingly, the $T_{t}-\bar{T}$ diagrams display staged kinetics, i.e. several plateaus, each for a specific metastable phase. This staged kinetics is found to be a general behavior of the cooling transformations, although different alloys may have a different metastable phase sequence. To demonstrate the generality of this type of behavior, several sets of experimental observations are presented here. For pure met- als, careful experimental studies ${ }^{11}$ have been made for $\mathrm{Co}, \mathrm{Fe}$, $\mathrm{Ti}$, and $\mathrm{Zr}$, and all display staged kinetics, as shown in Fig. 11 for pure Ti. ${ }^{11}$ For iron and iron alloys, many surveys have been made, and a comprehensive review has recently been written by Zhao. ${ }^{12}$ Similar behavior for Cu-Ga alloys has been observed by Kittl and Rodriguez ${ }^{13}$ and also Mirzayev and Schastlivtsev, ${ }^{11}$ as shown in Fig. 12 for a $\mathrm{Cu}-24$ at.\% Ga alloy. ${ }^{11}$ Similar results are found for $\mathrm{Cu}-\mathrm{Al}$ alloys. ${ }^{14}$

The fact that each metastable phase possesses its own $T_{s}\left(M_{s}\right.$, etc.) during cooling is crucial for the correct assessment of metastable phase information. For example, the " $M_{s}$ " points for Ti-Cr alloys, compiled by Murray, are shown in Fig. $13^{15}$ (data from Ref. 16 to 19); it is apparent that the " $M_{s}$ " points are widely scattered. It is demonstrated above that, within an appropriate cooling rate range in which a given metastable phase will form, the $T_{s}$ for that metastable phase is independent of cooling rate. In this connection, the $M_{s}$ points should not show the scatter seen in Fig. 13. This scatter is, in fact, due to the formation of different metastable phases (each possesses a different $M_{s}$ ). Carefully assessed $M_{a}$ and $M_{s}$ are shown in Fig. 14 (experimental data from Ref. 16 to 22). It is clear that the scatter for each $M_{a}$ and $M_{s}$ is relatively small.

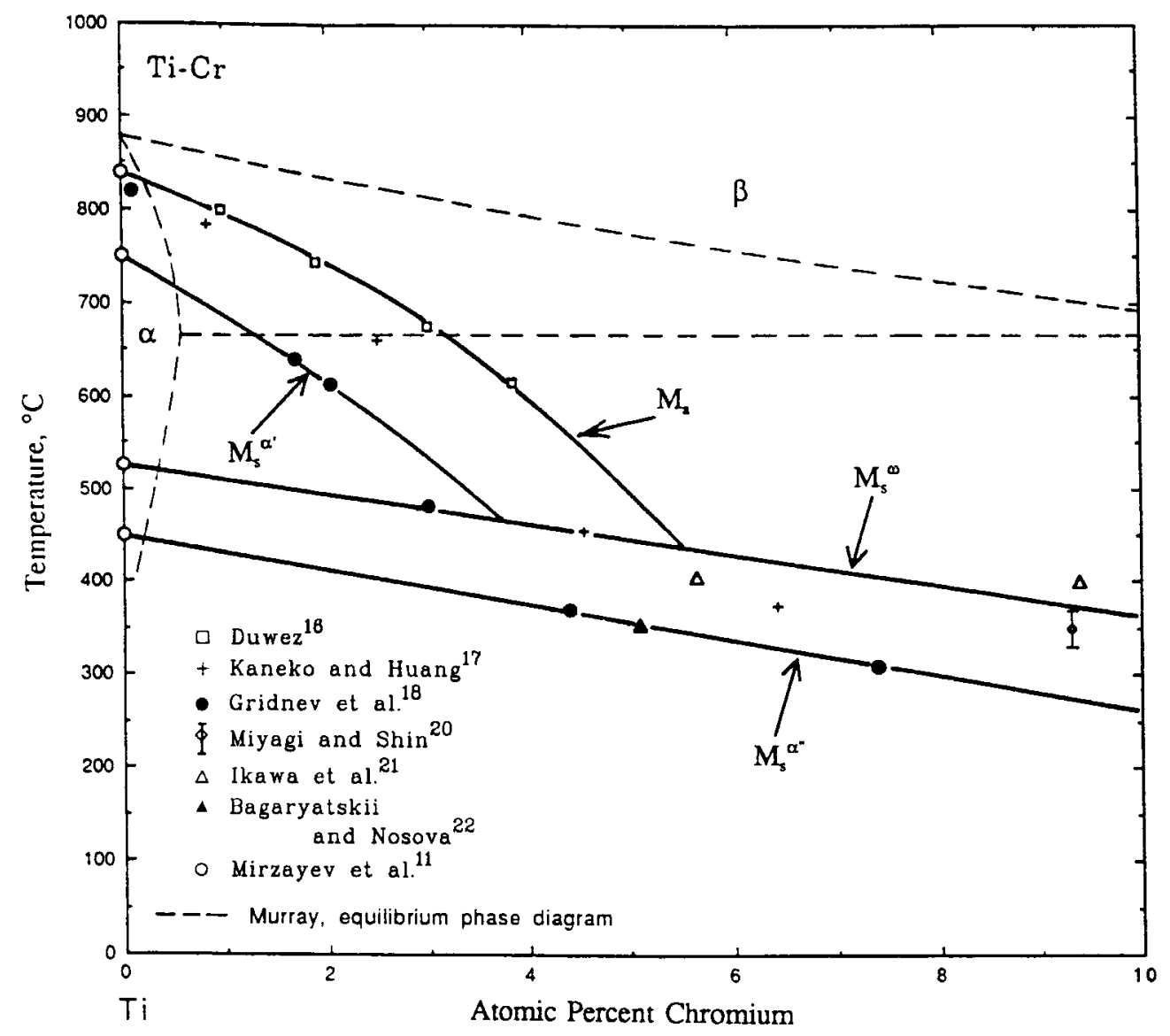

Fig. 14 Reassessment of the $\mathrm{M}_{\mathrm{a}}$ and $\mathrm{M}_{\mathrm{s}}$ of Ti-Cr alloys. $\mathrm{M}_{\mathrm{a}} \longrightarrow$ massive $\alpha$ transformation-start temperature; $\mathrm{M}_{\mathrm{s}}^{\alpha^{\prime}} \longrightarrow \alpha^{\prime}$ martensite transformation-start temperature; $\mathrm{M}_{\mathrm{s}}^{\omega}-\omega$ phase transformation-start temperature; and $\mathrm{M}_{\mathrm{s}}^{\alpha^{\prime \prime}}-\alpha^{\prime \prime}$ martensite transformation-start temperature. Data from Ref. 11, 16 to 18 , and 20 to 22 . 


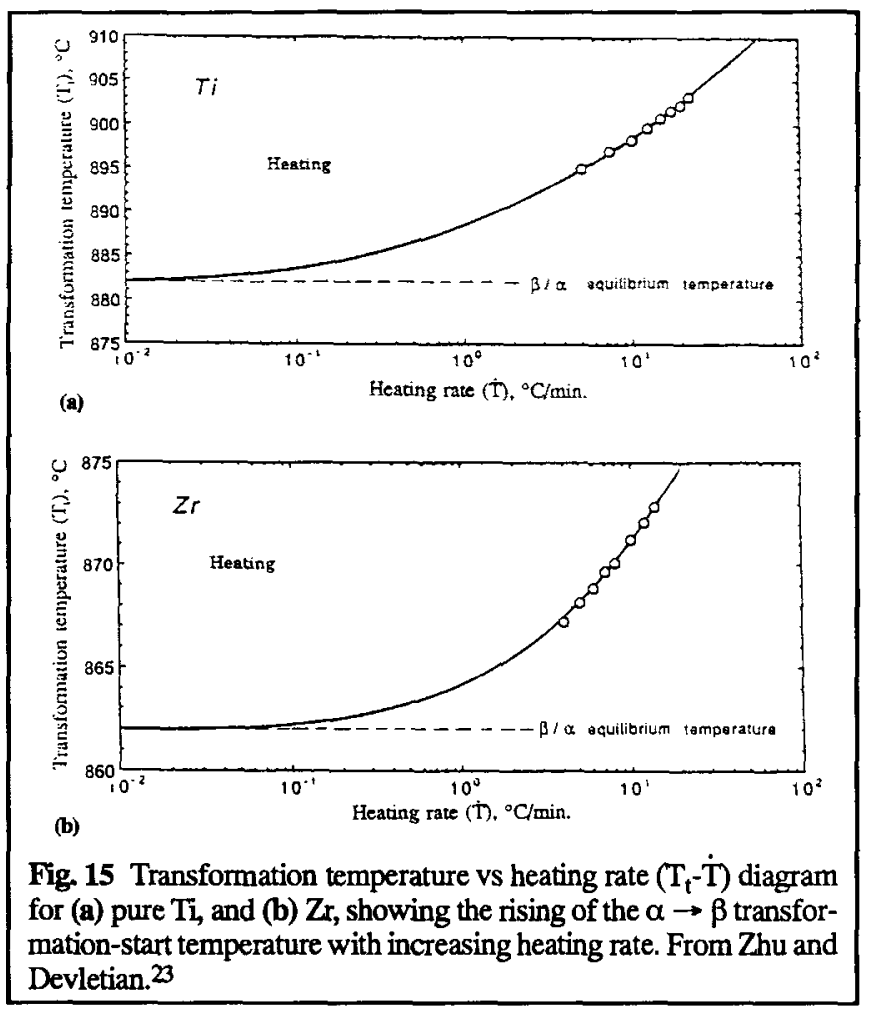

\section{Variation of the Transus with the Heating Rate}

Because transformations that occur during heating are similar to those that occur during cooling, the heating transformation also requires a certain superheating to nucleate a critical nucleus for the formation of the high-temperature phase. The heating transformation-start temperature $\left(T_{s}^{h}\right)$ shifts to higher temperatures with increasing heating rate, as shown in Fig. 15 for pure $\mathrm{Ti}$ and $\mathrm{Zr}^{23}$

As higher heating rates are reached, a massive transformation takes place, and its transformation-start temperature is independent of the heating rate, quite similar to the cooling process. Note that even though an alloy has a two-phase structure before heating, the $T_{s}^{\mathrm{h}}$ is still raised with increasing heating rate and reaches a plateau similar to the massive transformation of the type from single phase to single phase, as shown in Fig. 16 for a Ti-5.25 at.\% Mo alloy ${ }^{24}[(\alpha+\beta) \rightarrow \beta]$ and Fig. 17 for a Ti-4.6 at.\% Cr alloy ${ }^{25}[(\alpha+\gamma) \rightarrow(\alpha+\beta)]$. Similar results for the shifting of phase boundaries with heating rate are also found for iron and Fe-base alloys, ${ }^{26,27} \mathrm{Ti}$-base and $\mathrm{Zr}$-base alloys, ${ }^{23,28}$ and also Cu-base alloys. ${ }^{29}$

Note that when the cooling transformation is such that it has already produced metastable structures (martensite, for example), the subsequent heating transformation-start temperature is that of the metastable phase to an equilibrium phase and has little relation to the position of the equilibrium phase boundaries. This can be explained with the help of Fig. 18. If alloy $X_{0}$ is quenched from $T_{1}$ to $T_{2}$ with a high cooling rate, martensite is produced. When the specimen is heated, the transformationstart temperature is that of the martensite to $\beta$ phase (often des-

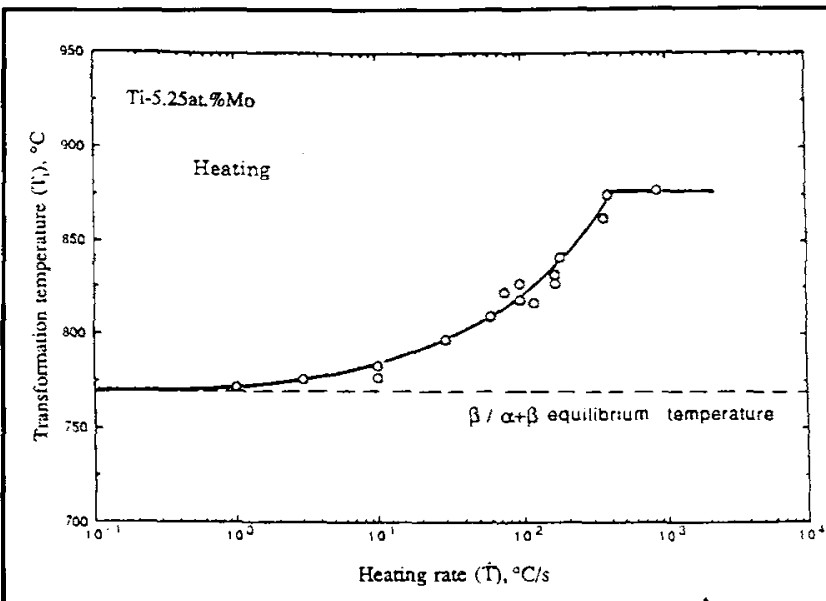

Fig. 16 Transformation temperature vs heating rate $\left(\mathrm{T}_{\mathrm{t}}-\dot{\mathrm{T}}\right)$ diagram of a Ti-5.25 at.\% Mo alloy, showing the shifting of the $\beta /(\alpha+\beta)$ transus with increasing heating rate. Data from Gridnev et al..$^{24}$

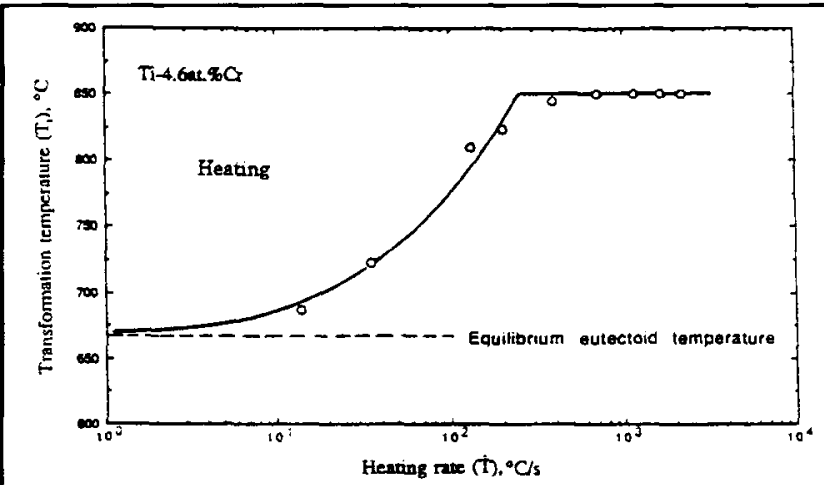

Fig. 17 Transformation temperature vs heating rate $\left(T_{t}-T\right)$ diagram of the $\mathrm{Ti}-4.6$ at. $\% \mathrm{Cr}$ alloy showing the shifting of the eutectoid temperature with increasing heating rate. Data from Gridnev et al. ${ }^{25}$

ignated as $A_{s}$ for steels) and has no direct relation with the $\beta /(\alpha$ $+\beta)$ transus. To determine the $\beta /(\alpha+\beta)$ transus, it is necessary to first anneal the specimen at $T_{2}$ (or other temperatures) for a sufficiently long time so that the martensite transforms completely to the equilibrium $(\alpha+\beta)$ phases. Then very slow heating can approach the transus. In this connection, the $A_{s}$ temperatures of steels seldom have direct relation to the $\gamma /(\alpha+$ $\gamma)$ transus. It is also worthwhile mentioning that the transformation-finish temperatures for both cooling and heating $\left(\mathrm{M}_{\mathrm{f}}\right.$, $A_{f}$, etc.) have little connection with the equilibrium transuses. Because the transformation-start temperatures are already shifted away from equilibrium, the finish temperatures are also shifted further away from equilibrium. Therefore, a description of the transformation-finish temperatures is not included in this discussion.

\section{Analysis of Examples}

\subsection{The $\gamma \leftrightarrow \alpha$ Equilibrium and Transformation In Fe-Ni Alloys}

As shown in Fig. 19, Swartzendruber et al. ${ }^{30}$ recently compiled a "transformation diagram" of the $\gamma \leftrightarrow \alpha$ transformation 
in Fe-Ni alloys, based on four previous investigations. ${ }^{31-34} \mathrm{We}$ believe this interpretation is incorrect. The data of Kaufman and Cohen ${ }^{31}$ are used to illustrate our argument. The transformation-finish temperatures are not shown in Fig. 20 because they have little relation to the equilibria, as discussed above. It is clear that the $T_{s}$ temperatures have been depressed from the $\gamma /(\alpha+\gamma)$ equilibrium transus; in high nickel alloys, the shift is especially dramatic. For example, at a cooling rate of $5^{\circ} \mathrm{C} / \mathrm{min}$

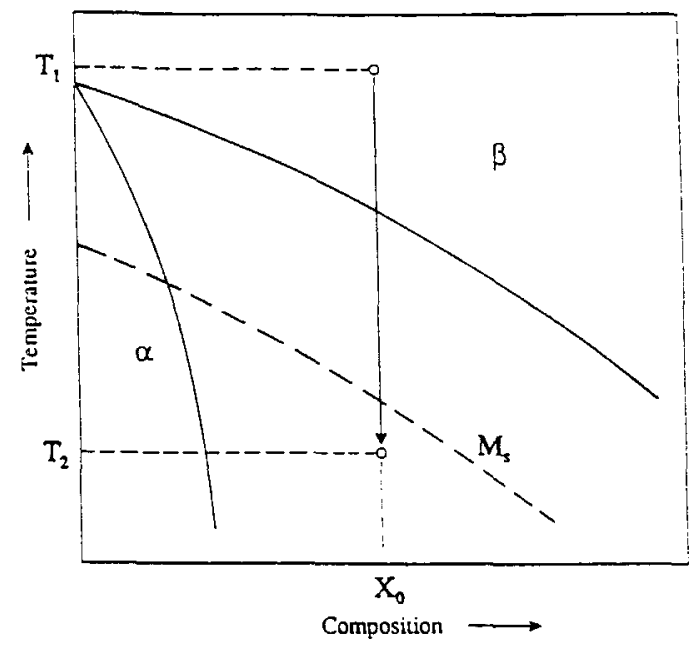

Fig. 18 Schematic diagram showing the formation of a metastable structure and the subsequent heating process. as used by Kaufman and Cohen, the transformation temperature for an $\mathrm{Fe}-30.7$ at.\% $\mathrm{Ni}$ alloy is depressed $\sim 570^{\circ} \mathrm{C}$, as shown by the vertical arrow in Fig. 20. If phase equilibrium information from diffusion couples and equilibrated alloys were not available and if only the cooling and heating transformation data were used to assess the $\gamma /(\alpha+\gamma)$ equilibrium transus, the obtained transus would be erroneous. It is therefore very dangerous to use only cooling and heating data to assess phase boundaries.

The heating transformation-start temperature $\left(A_{s}\right)$ should be above the $\gamma /(\alpha+\gamma)$ transus because heating always shifts the phase boundary to higher temperatures. The fact that the $A_{s}$ points are below the transus indicates that a metastable structure is produced during the cooling process, and therefore the A points are for the metastable phase to $\gamma$ phase transformation and have no direct relation to the equilibrium transus.

The carefully assessed $\mathrm{M}_{\mathrm{s}}, \mathrm{B}_{\mathrm{s}}$, and $\mathrm{M}_{\mathrm{a}}$ of $\mathrm{Fe}-\mathrm{Ni}$ alloys are shown in Fig. $21^{12}$ (data from Ref. 31 and 35 to 42). It is clear that each kind of metastable phase (massive ferrite, bainitic ferrite, lath martensite, and twinned martensite) has its own transformation-start temperature. Without such an analysis, the widely scattered " $M_{s}$ " points cannot be rationalized.

The " $M_{s}$ " line compiled by Swartzendruber et al. extends to $912{ }^{\circ} \mathrm{C}$, the equilibrium $\gamma / \alpha$ temperature for pure iron, as shown in Fig. 19. Although such a practice is often found in the literature, this is an incorrect assessment; martensite cannot be obtained for pure iron at the equilibrium $\gamma / \alpha$ temperature. The $M_{s}$ of pure iron for lath martensite and twinned martensite ${ }^{11,12}$ is 540 and $420^{\circ} \mathrm{C}$, respectively, as shown in Fig. 21.

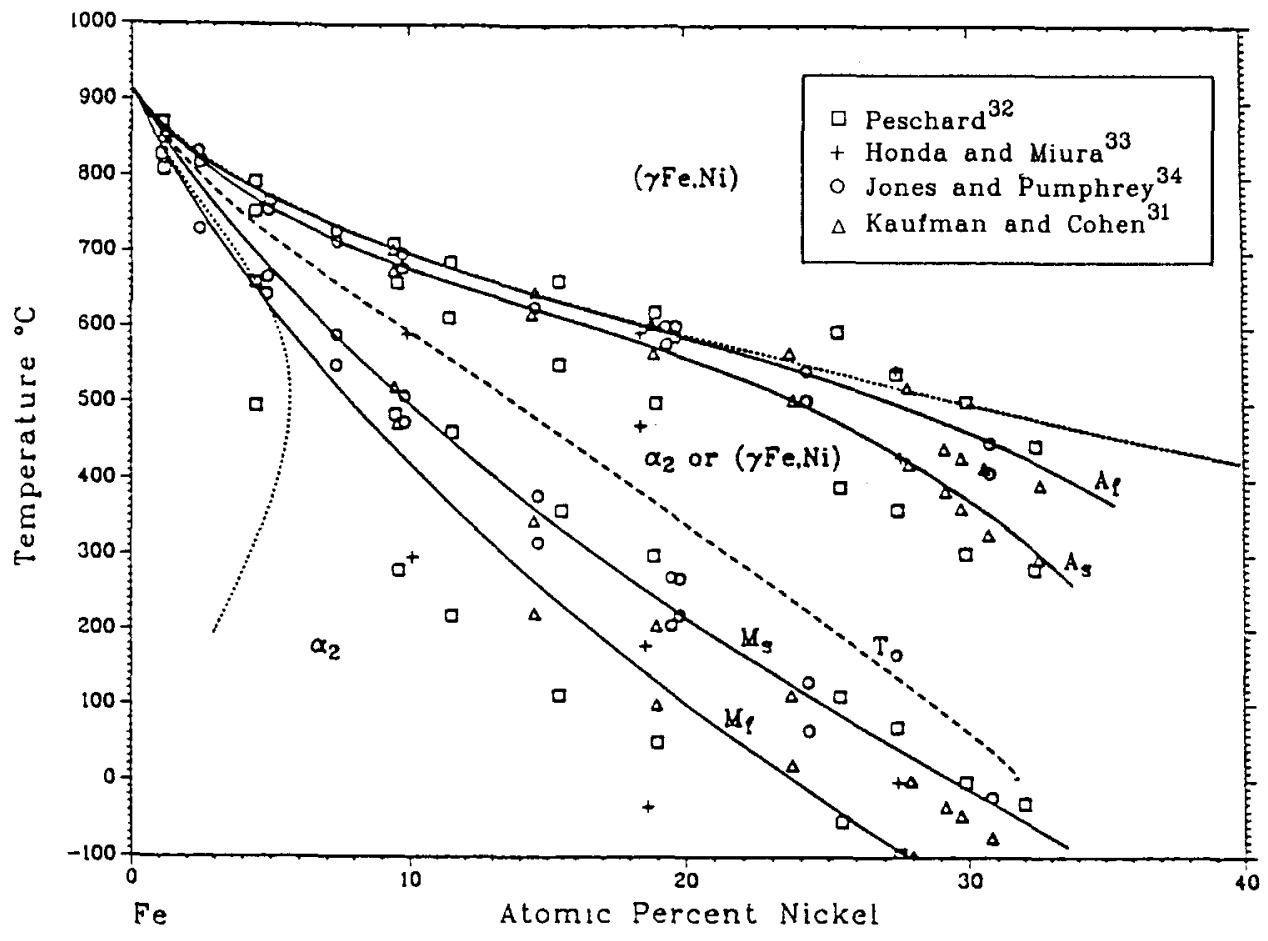

Fig. 19 "Transformation diagram" for Fe-Ni alloys compiled by Swartzendruber et al.30 Data from Ref. 31 to 34. 


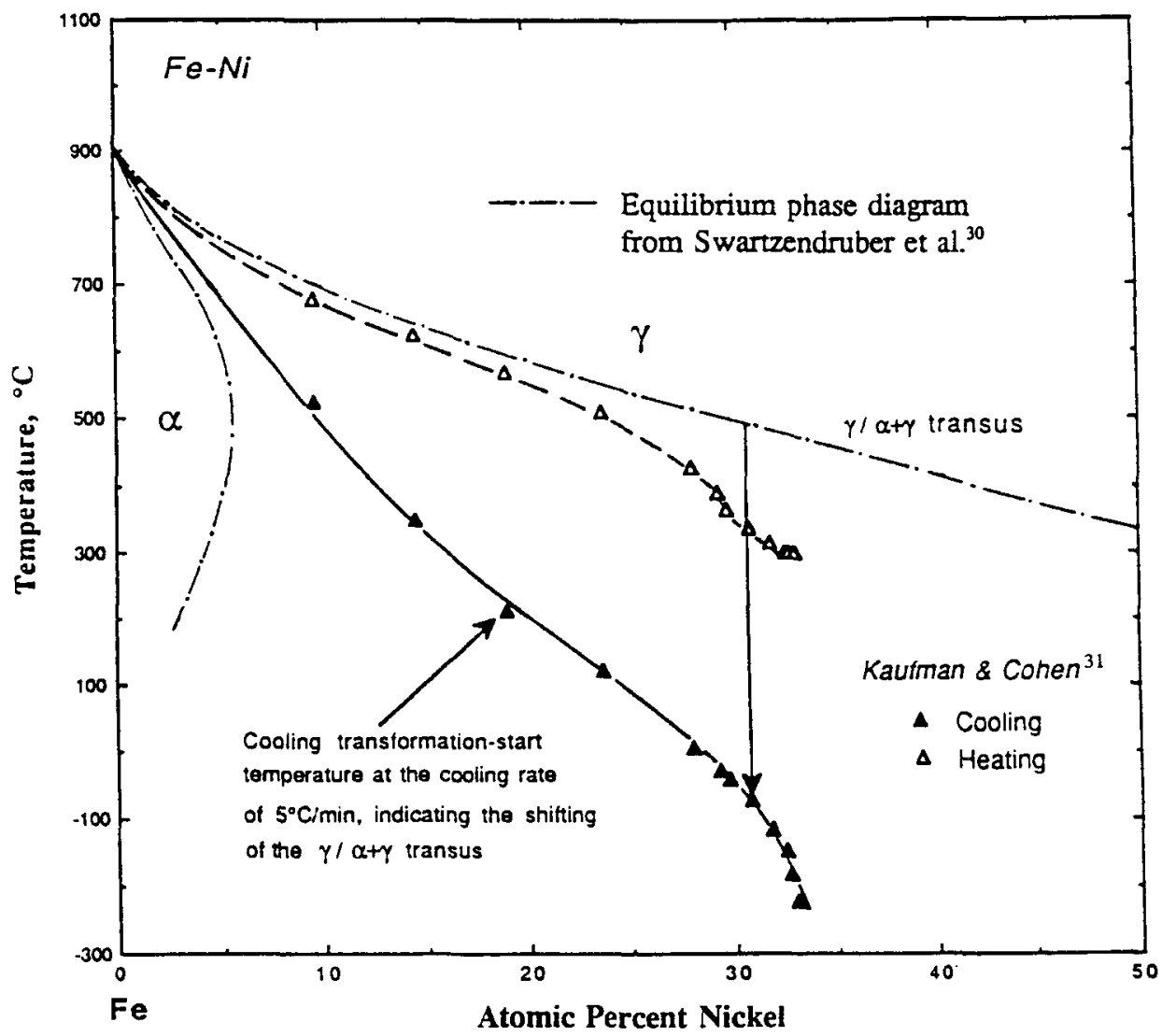

Fig. 20 Comparison of the cooling and heating transformation-start temperatures with the equilibrium $\gamma /(\alpha+\gamma)$ transus in Fe-Ni alloys, illustrating the manner in which the cooling process shifts the equilibrium.

\subsection{The $\beta /(\alpha+\beta)$ Transus in the Ti-Nb Binary System}

In assessing phase diagrams, it is often observed that the experimental data are widely scattered; a typical example ${ }^{43}$ is shown in Fig. 22 for the $\beta /(\alpha+\beta)$ transus of the Ti-Nb binary system (data from Ref. 44 to 49 ). Under such a circumstance, judgment must be used to determine which set of data is reliable for the assessment of the equilibrium phase boundary. The $\beta /(\alpha+\beta)$ transus as assessed by Murray ${ }^{43}$ is also shown in Fig. 22 ; this assessment is primarily based on the cooling transformation temperatures of Brown and Jepson. ${ }^{44}$ Because the cooling transformation temperatures can be depressed far away from the true equilibrium phase boundary, it is more reliable to assess the transus based on the results of Hansen et al. ${ }^{45}$ by means of the lattice parameter (XRD method), and the results of Ronami et al. ${ }^{46}$ by means of diffusion couple specimens. Thus we propose that the $\beta /(\alpha+\beta)$ transus should be much higher than that assessed by Murray, as we indicate in Fig. 22.

\section{Summary and Discussion}

Typical cooling transformation characteristics can be summarized in Fig. 23, using $\mathrm{Fe}-\mathrm{Mn}$ alloys ${ }^{12}$ as an example. In the low-cooling-rate range $\left(<1000^{\circ} \mathrm{C} / \mathrm{s}\right.$ for $\mathrm{Fe}-1.22$ at. $\% \mathrm{Mn}$ al- loy), the higher the cooling rate the lower the transformationstart temperature, i.e. the further away from equilibrium, as shown in Fig. 23(b). ${ }^{50}$ Above a certain critical cooling rate $\left(\sim 100{ }^{\circ} \mathrm{C} / \mathrm{s}\right.$ for $\mathrm{Fe}-1.22$ at.\% $\left.\mathrm{Mn}\right)$, the transformation temperature becomes independent of the cooling rate and several plateaus appear in the $T_{t}-\dot{T}$ diagram. These plateaus (stages) signify the formation of various metastable phases, and they indicate that each kind of metastable phase possesses its own transformation-start temperature, which is independent of the cooling rate. When the results of several investigations are put together, as shown in Fig. 23(a), ${ }^{12}$ distinct transformation-start temperatures $\left(\mathrm{M}_{\mathrm{a}}, \mathrm{B}_{\mathrm{s}}\right.$, and $\left.\mathrm{M}_{\mathrm{s}}\right)$ for various metastable phases (massive ferrite, bainitic ferrite, lath martensite, and twinned martensite) are evident.

The cooling and heating results may be superimposed as shown schematically in Fig. 24 so that the shifting of the phase boundaries with both heating and cooling can be analyzed at the same time. The transformation-start temperatures of cooling and of heating are associated with the $\beta /(\alpha+\beta)$ and $\alpha /(\alpha+\beta)$ transus, respectively, so that at very slow cooling and heating rates, the transformation temperature of cooling should be higher than that of heating, as shown in Fig. 24. As higher and higher cooling rates are used to determine the $\beta /(\alpha+\beta)$ transus, the measured phase boundary can be shifted all the way from the equilibrium $\beta /(\alpha+\beta)$ transus temperature down to the $M_{a}$ 


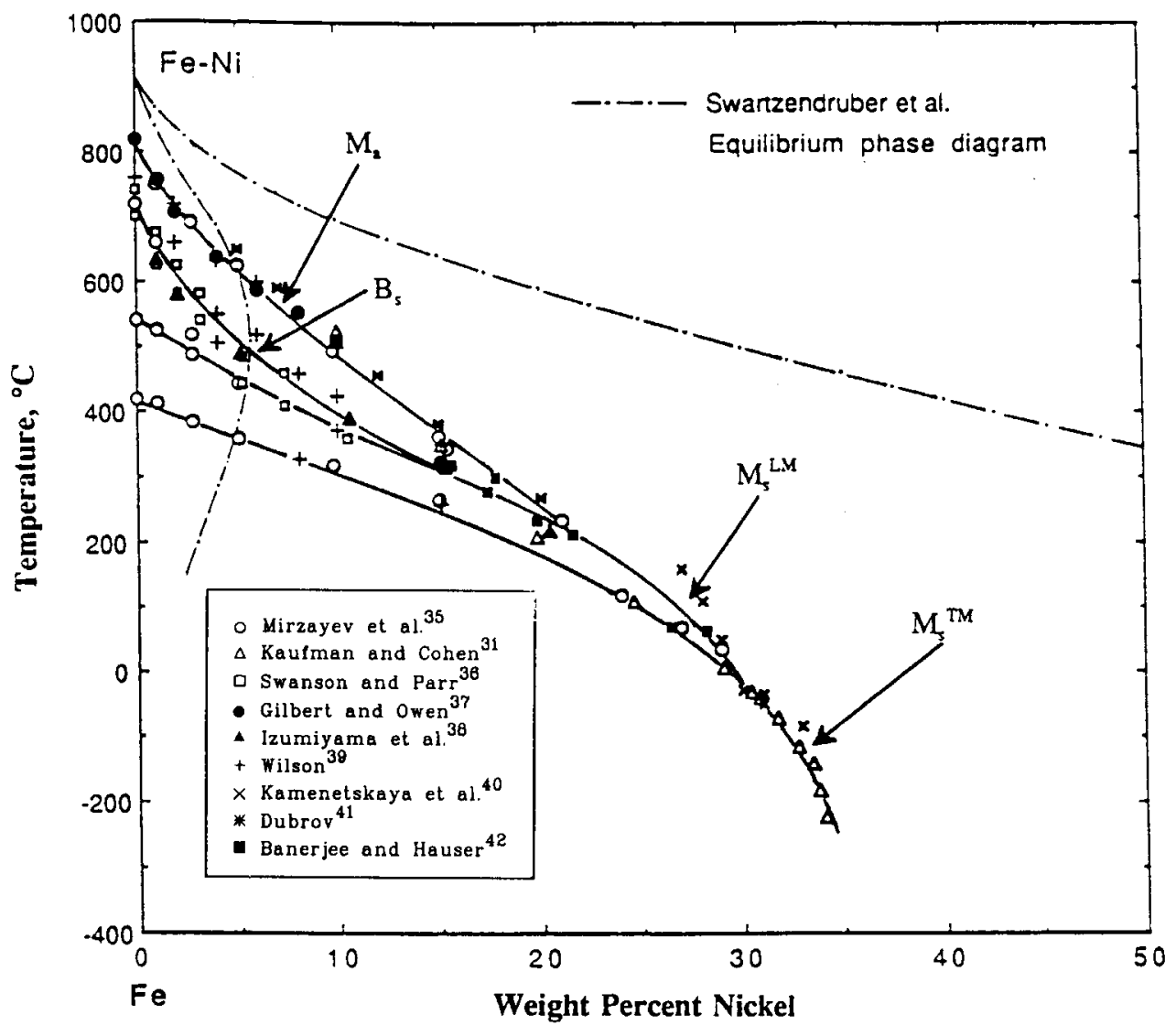

Fig. 21 The assessed $\mathrm{M}_{\mathrm{a}}, \mathrm{B}_{\mathrm{s}}$, and $\mathrm{M}_{\mathrm{s}}$ of Fe-Ni alloys. ${ }^{12} \mathrm{M}_{\mathrm{a}}$-massive ferrite transformation-start temperature; $\mathrm{B}_{\mathrm{s}}-$ bainitic ferrite transformationstart temperature; $M_{s}^{L M}$ _lath martensite transformation-start temperature; and $M_{s}^{T M}$ — twinned martensite transformation-start temperature. Experimental data from Ref. 31 and 35 to 42 .

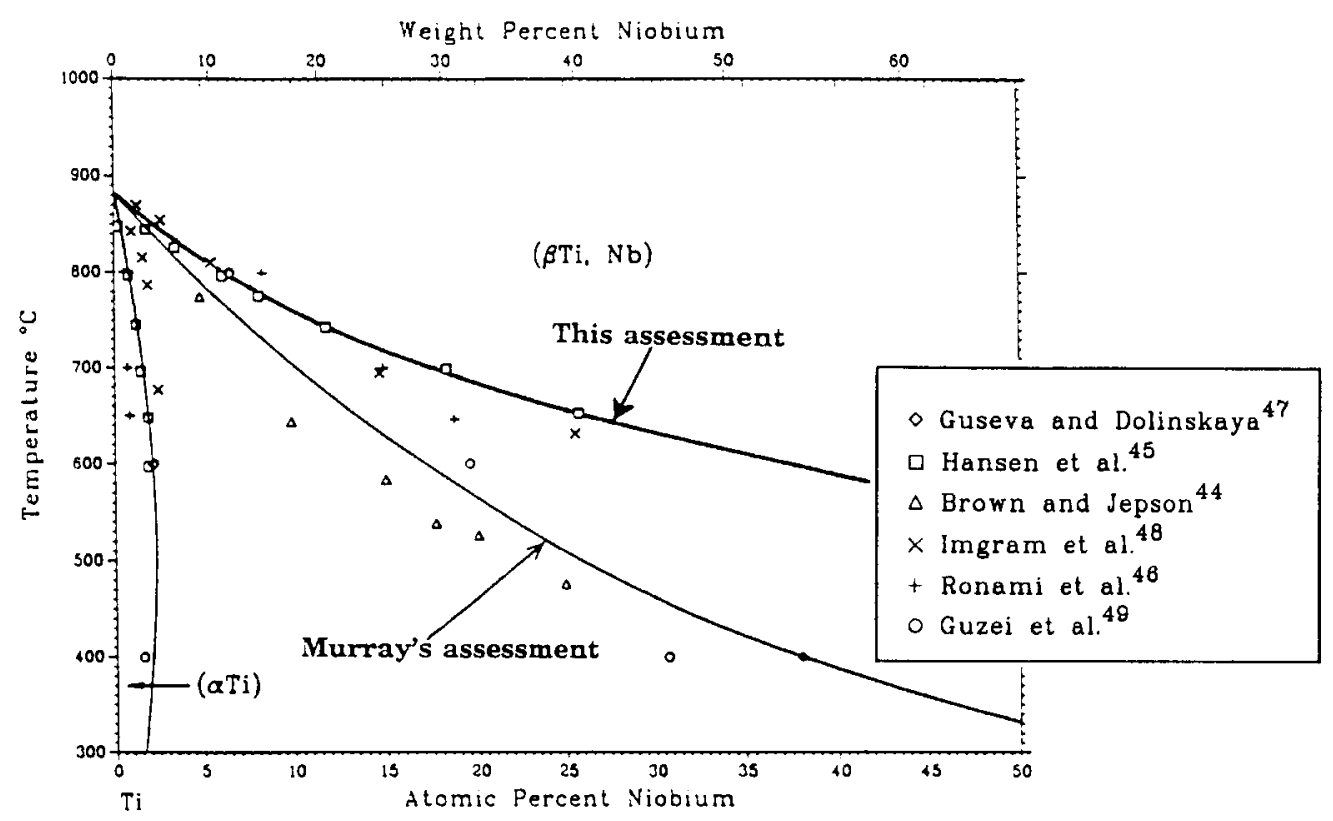

Fig. 22 Part of the Ti-Nb binary phase diagram illustrating the difference between this assessment and Murray's. ${ }^{43}$ Experimental data from Ref. 44 to 49. 


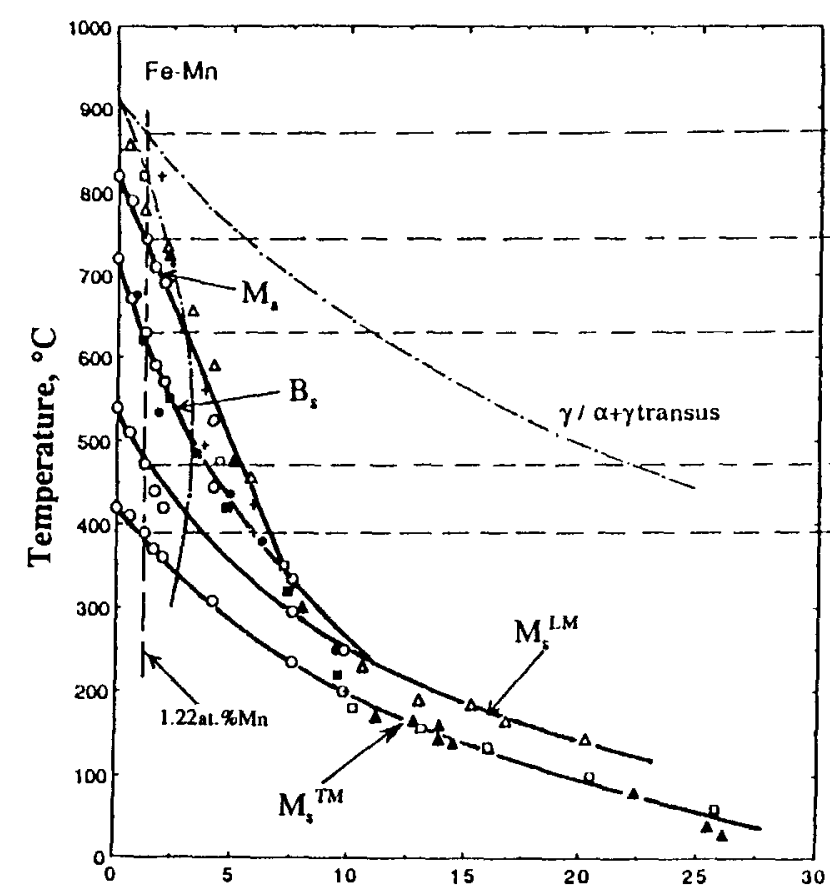

(a)

Weight Percent Manganese

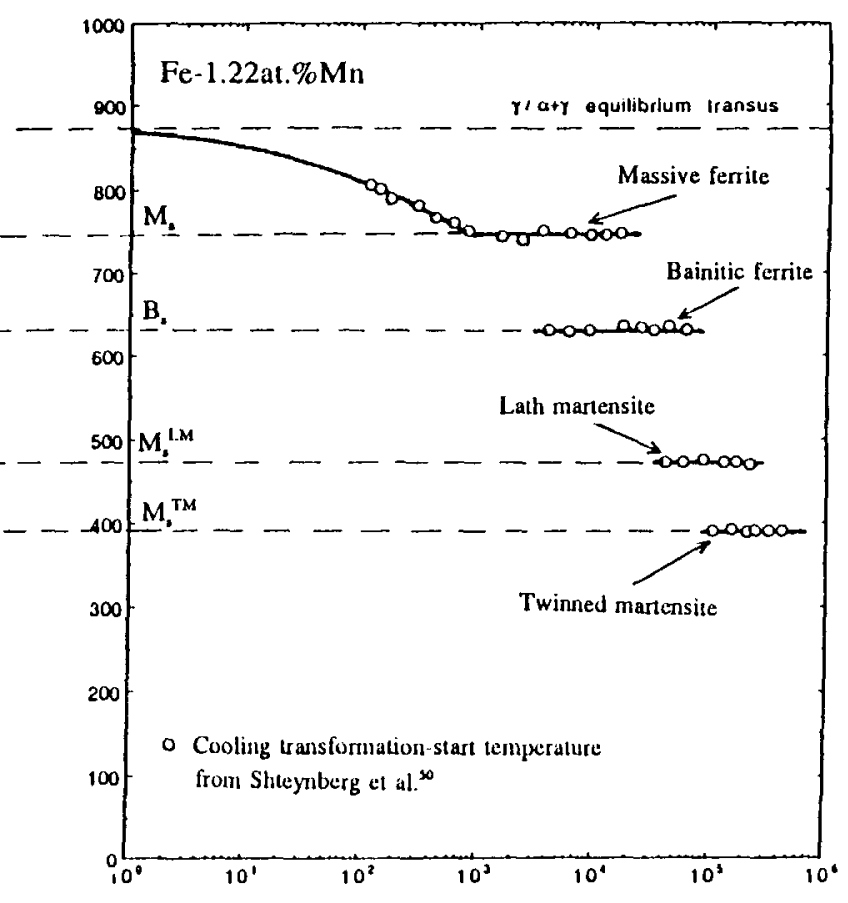

(b)

Fig. 23 Equilibrium state and metastable states in Fe-Mn alloys during cooling. (a) Transformation-start temperatures of various metastable phases superimposed on the equilibrium phase diagram. $\mathrm{M}_{\mathrm{a}}$-massive ferrite transformation-start temperature; $\mathrm{B}_{\mathrm{s}}-$ bainitic ferrite transformation-start temperature; $\mathrm{M}_{\mathrm{s}}^{\mathrm{LM}}$ — lath martensite transformation-start temperature; and $\mathrm{M}_{\mathrm{s}}^{\mathrm{TM}} \rightarrow$ twinned martensite transformation-start temperature. For key to the experimental data, see Ref. 12. (b) $\mathrm{T}_{\mathrm{t}}-\mathrm{T}$ diagram of the Fe-1.22 at.\% $\mathrm{Mn}$ alloy, ${ }^{50}$ showing that only at very low cooling rates the equilibrium can be approached, at higher cooling rates the equilibrium is shifted away, and at very high cooling rates $\left(>1000^{\circ} \mathrm{C} / \mathrm{s}\right)$ various metastable states (i.e. metastable phases) appear.

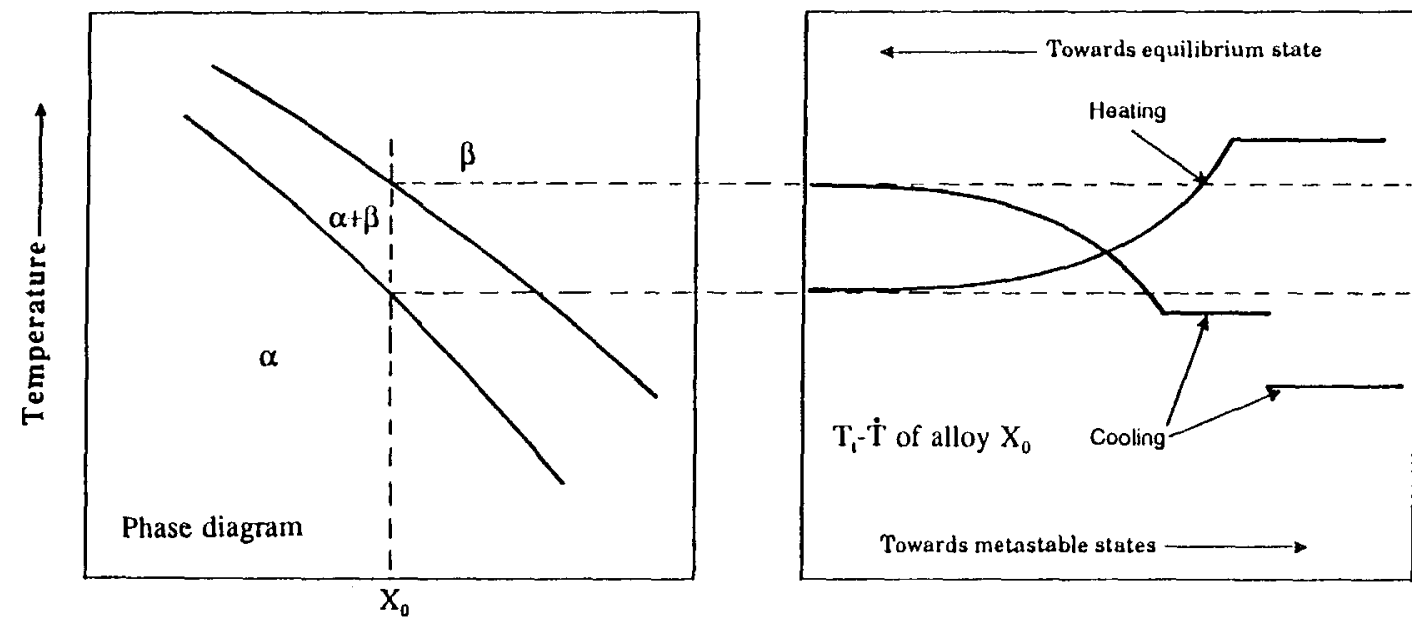

(a)

Composition $\longrightarrow$

(b) Cooling or heating rate $(\dot{\mathrm{T}}) \longrightarrow$

Fig. 24 Aschematic diagram illustrating the way both the cooling and heating processes shift the equilibrium.

temperature, i.e. any temperature between the equilibrium $\beta /(\alpha+\beta)$ transus and $M_{a}$ point is possible, as schematically shown in Fig. 24. Similar behavior may also be observed for the $\alpha /(\alpha+\beta)$ transus during the heating process. At very high cooling and heating rates, the transformation temperature of cooling can become even lower than that of heating. If this behavior is observed, it signifies that the results are already far from equilibrium. This behavior is often the cause of the scatter of experimental data. If the cooling or heating rate is high enough to initiate a metastable phase transformation, then the 
$M_{s}$ data will have relatively less scatter because the $M_{s}$ for metastable phase transformation is independent of cooling rate, as shown in Fig. 21 for Fe-Ni alloys and Fig. 23 for Fe-Mn alloys.

The specific values of "high" cooling and heating rates that cause significant deviation from equilibrium depend on the composition, grain size, and phase structure of the alloy. Unfortunately it is not presently possible to predict which cooling or heating rate would be high enough for a specific alloy to cause significant deviation and how far the equilibrium value will be shifted. However, note that if the high-temperature phase is liquid, the shifting of the phase boundary during slow cooling and heating is less pronounced than that of solid-solid phase transformations because it is much easier to nucleate a critical nucleus from a liquid than from a solid phase. In this connection, the normal thermal analysis method (at very slow cooling and heating) is a good approach to determine equilibrium liquidi. As shown in Fig. 20 for high nickel Fe-Ni alloys, for solid-solid transuses, especially at low temperatures, sometimes even a few degrees per minute is a high cooling rate because diffusion is difficult. Under these circumstances, it is recommended to make full use of the results of equilibrated alloys or diffusion couples (the second category of methods as discussed in section 1) to assess phase boundaries.

\section{Cited References}

1. R.D. Shull, Bull. Alloy Phase Diagrams, 4, 5-15(1983).

2. B. Feuerbacher, Mater. Sci. Rep., 4, 1-40(1989).

3. W.W. Scott, Jr., H. Baker, and L. Kacprzak, Computerizing and Networking of Materials Data Bases, ASTM, STP 1017, J.S. Glazman and J.R. Rumble, Jr., Ed., ASTM, Philadelphia, 322-328(1989).

4. M.R. Plichta, H.I. Aaronson, and J.H. Perepezko, Acta Metall, 26, 1293-1305 (1978).

5. G.F. Vander Voort, Atlas of Time-Temperature Diagrams for Irons and Steels, ASM International, Materials Park, OH(1991).

6. E.B. Hawbolt and T.B. Massalski, Metall. Trans., 2, 1771-1777 (1971).

7. J.H. Perepezko, Proc. Inth Conf. Solid $\rightarrow$ Solid Phase Transformations, H.I. Aaronson, D.E. Laughlin, R.F. Sekerka, and C.M. Wayman, Ed., TMS-AIME, 231-235 (1982).

8. T.B. Massalski, Phase Transformations, American Society for Metals, Metals Park, OH, 433-483 (1970).

9. L.P. Srivastava and J.G. Parr, Trans. TMS-AIME, 224, 1295-1297 (1962).

10. D.A. Mirzayev, S.Ye. Karzunov, V.M. Schastlivtsev, I.L. Yakovleva, and Ye.V. Kharitonova, Fiz Metal. Metalloved, 61, 331$338(1986)$

11. D.A. Mirzayev and V.M. Schastlivtsev, Proc. Intl. Conf. Martensitic Transformations (ICOMAT'86), Japan Institute of Metals, 282-287 (1986).

12. J. Zhao, Mater. Sci. Technol, 8, 997-1003 (1992).

13. J.E. Kittl and C. Rodriguez, Acta Metall., 17, 925-928(1969).

14. J. Jellison and E.P. Klier, Trans. TMS-AIME, 233, 1694-1702 (1965).

15. J.L. Murray, Phase Diagrams of Binary Titanium Alloys, ASM International, Metals Park, OH, 68-78 (1987).

16. P. Duwez, Trans. ASM, 45, 934-940 (1953).

17. H. Kaneko and Y.C. Huang, J. Jpn. Inst. Met. , 27, 393-397 (1963).
18. V.N. Gridnev, V.I. Trefilov, D.V. Lotsko, and N.F. Chernenko, Sb. Nauchni. Tr. Inst. Metallofiz, Akad. Nauk Ukr. SSR, 12, 37-44 (1961).

19. P.D. Frost, W.M. Parris, L.L. Hirsch, J.R. Doig, and C.M. Schwartz, Trans. ASM, 46, 231-256(1954).

20. M. Miyagi and S. Shin, J.Jpn Inst. Met., 35, 716-722(1971).

21. H. Ikawa, S. Shin, and M. Morikawa, Yosetsu Gakkaishi, 41, 394402(1972).

22. Yu.A. Bagaryatskii and G.I. Nosova, Fiz. Metal. Metalloved, 13, 415-425 (1962).

23. Y.T. Zhu and J.H. Devletian, Metall Trans. A, 22, 1993-1998 (1991).

24. V.N. Gridnev, A.F. Zhuravlev, B.F. Zhuravlev, O.M. Ivasishin, and S.P. Oshkaderov, Fiz. Metal. Metalloved, 56, 985-991 (1983).

25. V.N. Gridnev, Yu. Ya. Meshkov, and N.F. Chernenko, Sb. Nauchni Tr. Inst. Metallofiz, Akad. Nauk Ukr. SSR, 17, 143-146 (1963).

26. W.L. Haworth and J.G. Parr, Trans. ASM, 58, 476-488 (1965).

27. V.N. Gridnev, V.G. Gavrilyuk, S.P. Oshkaderov, Neue Hüette, 28 , 361-368(1983).

28. V.N. Gridnev, O.M. Ivasishin, and P.E. Markovskii, Metal Sci. Heat Treat., 27, 43-48(1985).

29. V.N. Gridnev, Martensitnye Prevrashch, Dokl. Mezhdunar Konf "ICOMAT-77", Gridnev, Ed., Izd. Naukova Dumka, Kiev, USSR, 246-252 (1978).

30. L.J. Swartzendruber, V.P. Itkin, and C.B. Alcock, J. Phase Equilibria, 12, 288-312 (1991).

31. L. Kaufman and M. Cohen, Trans. AIME, 206, 1393-1401 (1956).

32. M. Peschard, Rev. Metall, 22, 430-676(1925).

33. K Honda and S. Miura, Sci. Rep. Tôhoku Imp. Univ, 16, 745-753 (1927).

34. F.N. Jones and W.I. Pumphrey, J. Imn Steel Inst, 163, 121-131 (1949).

35. D.A. Mirzayev, O.P. Morozov, and M.M. Shteynberg, Fiz Metal. Metalloved, 36, 560-568(1973).

36. W.D. Swanson and J.G. Parr, J. Iron Steel Inst., 202, 104-106 (1964).

37. A. Gilbert and W.S. Owen, Acta Metall, 10, 45-54 (1962).

38. M. Izumiyama, M. Tsuchiya, and Y. Imai, Sci. Rep. Res. Inst. Tôhoku Univ., 22A, 93-104(1970).

39. E.A. Wilson, Metal Sci., 18, 471-484 (1984).

40. D.S. Kamenetskaya, O.P. Maksimova, and V.I. Shiryayev, Fiz Met. Metalloved, 55, 967-972(1983).

41. V.A. Dubrov, Fiz. Met. Metalloved, 21, 551-554 (1966).

42. B.R. Banerjee and J.I. Hauser, Metallography, 1, 157-159 (1948).

43. J.L. Murray, Phase Diagrams of Binary Titanium Alloys, ASM International, Metals Park, OH, 188-194 (1987).

44. A.R.G. Brown and K.S.Jepson, Mem. Sci.Rev.Metall.,63,575-584 (1966).

45. M. Hansen, E.L.Kamen, H.D. Kessler, and D.J. McPherson, Trans. AIME, 191, 881-888(1951).

46. G.N. Ronami, S.M. Kuznetsova, S.G. Fedotov, and K.M. Konstantinov, Vestr. Mosk. Univ., Fiz., 25, 186-189 (1970).

47. L.N. Guseva and L.K. Dolinskaya, Dokl Akad. Nauk SSSR, 266 , 634-637(1982).

48. A.G. Imgram, D.N. Williams, R.A. Wood, H.R. Ogden, and R.I. Jaffee, WADC Tech. Rep. 59-595, Battelle Memorial Inst. (1961).

49. L.S. Guzei, E.M. Sokoloyskaya, and A.T. Grigor'ev, Vestn. Mosk. Univ, Khim, 21, 406-409 (1966)

50. M.M. Shteynberg, D.A Mirzayev, and T.M. Ponomareva, Fiz. Met. Metalloved, 43, 166-172(1977). 